\title{
PHARMACIST ROLE IN GLOBAL HEALTH: A REVIEW OF LITERATURE
}

\author{
TUQA HAITHAM ALLAYLA ${ }^{1 *}$, AHMED IBRAHIM NOURI² AND MOHAMED AZMI \\ HASSALI ${ }^{1}$ \\ 1Discipline of Social and Administrative Pharmacy, School of Pharmaceutical Sciences, \\ 11800 USM, Pulau Pinang, Malaysia \\ ${ }^{2}$ Discipline of Clinical Pharmacy, School of Pharmaceutical Sciences, \\ 11800 USM, Pulau Pinang, Malaysia
}

\section{Published online: 23 October 2018}

To cite this article: TUQA HAITHAM ALLAYLA, AHMED IBRAHIM NOURI \& MOHAMED AZMI HASSALI (2018) Pharmacist role in global health: A review of literature, Malaysian Journal of Pharmaceutical Sciences, 16(1): 45-54, https://doi.org/10.21315/ mjps2018.16.1.4.

To link to this article: https://doi.org/10.21315/mjps2018.16.1.4

Emergence of various global health problems has widened the pharmacist's job scope. An accessible resource for health and medication information as the pharmacist strengthen the existing public health system. Achievement of optimal patient outcomes involves community and clinical pharmacist safe and effective medication use. However, the public is still unaware of the pharmacist's role in public and global health. This essay aims to identify pharmacist's role in overcoming global health problems with a literature review. Pharmacists' role change from public care provider to public care profession. The roles of pharmacists in health care team as primary care practitioners can be seen in their management of tropical and chronic diseases. With their evaluation skills and extensive knowledge of drugs. Pharmacists can provide the best medical advice to the patients besides promoting selftreatment on minor ailments. Furthermore, they also help in reducing the medical costs and optimising medications for the patients. The faith of the public in pharmacists on vaccination proves that they accept the involvement of pharmacists in healthcare provision. However, the public awareness towards pharmacists' role should be improved.

Keywords: Global health, Pharmacist, Disease, Community pharmacist, Literature review

\section{INTRODUCTION}

The traditional fundamental role of pharmacists is to dispense drugs that were prescribed by the physician. However, in the recent years, the pharmacists' roles have been expanding around the globe. Nowadays, pharmacists play a vital role among the medical professions through the medicine and information they provide. As one of the most accessible and trusted health care providers, pharmacists play an important role in public health and global health areas including disaster preparedness, immunisations, and preventive health

"Corresponding author: tuqa.haitham@yahoo.com

(C) Penerbit Universiti Sains Malaysia, 2018. This work is licensed under the terms of the Creative Commons Attribution (CC BY) (http://creativecommons.org/licenses/by/4.0/). 
measures. The pharmacists' services include more patient-oriented, administrative and public health functions (Steeb, Joyner and Thakker 2014).

Other than that, pharmacists bring the right medicines to patients who need them. There are many functions of public health that can benefit from pharmacists' unique expertise that may include pharmacotherapy, access to care, and prevention services. Apart from dispensing medicine, pharmacists have proven to be an accessible resource for health and medication information. The pharmacists' centralised placement in the community and clinical expertise are invaluable. The profession of pharmacy has undergone a similar metamorphosis that is from a concentration on medication dispensing to a focus on safe and effective medication use to achieve optimal patient outcomes (Steeb, Joyner and Thakker 2014).

Public health is "what we, as a society do collectively to assure the condition for people to be healthy" (American Public Health Association 2006). Through the execution of essential health services, public health has evolved through a variety of stages to arrive at sustaining community health and quality of life. Through shared responsibility, the pharmacists are equipped to strengthen the existing public health system. Pharmacists have many functions that align with those of the essential health services that are critical to public health.

The role of the pharmacists in public health has been defined and the literature is limited concerning the role of the pharmacists in global health (Macfarlane, Jacobs and Kaaya 2008). The executive board of the Consortium of Universities for Global Health $(\mathrm{CUGH})$ had given the suggestions that the word "global" should be referred to the scope of a problem rather than a geographic location. Instead of that, $\mathrm{CUGH}$ also suggest that the concept of global health can be applied to health challenges in developing countries such as emerging infectious diseases and issues surrounding maternal, child health, and health issues that can be found in the community, such as cardiovascular diseases, diabetes and other non-communicable diseases (Steeb, Joyner and Thakker 2014). In particular, pharmacists can look at the varied global health careers established in medicine and use this as a framework to understand the potential role of the pharmacist within global health practice and program delivery, research, and policy. In March 2016, the Board of Pharmaceutical Practice adopted the following definition of a pharmacist: "A pharmacist is a scientifically-trained graduate healthcare professional who is an expert in all aspects of the supply and use of medicines. Pharmacists assure access to safe, cost-effective and quality medicines and their responsible use by individual patients and healthcare systems" (International Pharmaceutical Federation [FIP] 2017).

Based on the policy statement published by American Public Health Association in 2006 entitled Role of the Pharmacists in Public Health, the role of pharmacists as a profession continues to shift from product-centred to patient-centred services (American Public Health Association 2006). A report by United States (US) Public Health Service's landmark year 2011 stated that a pharmacist can improve health outcomes through an advanced pharmacy practice. Nowadays, pharmacists become one of the most accessible and trusted health care providers and also play a vital role in many public health areas including disaster preparedness, immunisation and preventive health measures (Steeb, Joyner and Thakker 2014). Pharmacists are not only public health care providers but also contributors to the public health through activities that include delivering immunisations, conducting screenings for various acute and chronic diseases states and promoting proper drug use. Pharmacists also serve as health and prevention educators in a variety of clinical and community settings. As the role of pharmacists in global health evolves, there needs to be a similar evolution in how one perceives the services pharmacists provide and where these services can be applied (Strand et al. 2016).

Malay J Pharm Sci, Vol. 16, No. 1 (2018): 45-54 


\section{ROLE OF PHARMACISTS IN GLOBAL HEALTH}

Pharmacists practice roles in public health goals are increasing healthy life years, quality and eliminating health disparities. This is achievable by patient education, motivation, and opportunities for informed health decisions. Pharmacists participate in health fairs, provide health education seminars in the community and perform blood pressure screening, blood glucose monitoring, memory screening, brown bag session counselling, etc. Pharmacists play a crucial role in providing services like drug administration and optimise medication use (Traynor 2005). Patient counselling is given including provision of oral and written drug product information, such as common side effects, proper storage and administration, and doses scheduling, intended use and lifestyle information for behavioural changes that enhance wellness (Vivian and Fink III 2008).

Nowadays, pharmacists are providing a wide range of public health including smoking cessation, National Health Service (NHS) health checks and weight management. The scheme had shown positive results with the majority of services evaluated with improved quality outcomes and positive feedback from the public. Pharmacists' clinical skills are more emphasised and becoming more important. For example, community pharmacies play an important role in the early detection of cancer (NHS England 2013). There is increasing collaboration between community pharmacist and general practitioners (GPs).

Pharmacists also manage clinics for chronic diseases such as human immunodeficiency virus (HIV), mental health disorders, hyperlipidaemia, diabetes, anticoagulation and hypertension. Other services provided include immunisations, smoking cessation programmes, prevention and wellness programs. Pharmacist-run clinics can facilitate improved patient adherence, targeted drug therapy monitoring and provide access to comprehensive medication therapy management (MTM) services, drug utilisation review (DUR), patient counselling standards and maintaining patient records (Vivian and Fink III 2008). However, public awareness about pharmacy services is still limited. Steps in educating and creating awareness should be given priority to allow pharmacists to serve the community (The Royal Pharmaceutical Society England 2013).

Global health focuses on prevention in populations and clinical care in individuals and promoting health equity among people on a global scale. Clinical pharmacists play a significant role by providing information and advice on the therapeutic use of medicines. In rural South Africa, a care model for mental health disorders, substance abuse and HIV infection and acquired immune deficiency syndrome (AIDS) is seen to be collaboration between the clinical pharmacist and community-based organisations. The purpose includes promoting diabetes and nutrition awareness and call for an increase in maternal and child health services. In Lesotho, an assessment is carried out on medication storage by pharmacy and practices are given among primary caregivers and adolescent patients to improve patient's safety in a paediatric HIV clinic. Pharmacist carried out motion in initiatives and efforts to translate innovative models of care for chronic diseases into public health policy in the Mississippi Delta, US (Oji et al. 2013).

As the global healthcare systems continue to develop, pharmacists are one of the expected factors to increase the self-care treatment for minor ailments. The global health system is aimed to go through significant changes in the future to remain economically viable. Health care consumers who are taking proactive roles in identifying managing their health will characterise their self-care to optimise their whole physical, spiritual and psychological well-being (Bell et al. 2016). Furthermore, pharmacists help to provide important and valuable information to make sure the consumers have proper and appropriate treatments. 


\section{PHARMACIST CONTRIBUTION IN VARIOUS MEDICAL ILLNESSES}

Community pharmacists deal with hyperlipidaemia, hypertension and secondary prevention medications to enhance surrogate results for cardiovascular disease's patients (George et al. 2010). The pharmacists' role includes conveying to the patients the desired targets and results to improve their therapeutic consent and adherence such as explain the recommended doses to the patients and advise them to proceed with a medication regimen until being stopped to do so by any health care providers. They also appraise gaps in treatment (e.g., missing medication, overuse or underuse of medication in a regimen), cooperate with health care providers, and being dynamic and active participants in remedial decision making to guarantee that patients' treatment is applicable to achieve the desired outcomes (George et al. 2010). Pharmacists have a chance for intervention by associating physicians on therapeutic follow-up such as providing information about refill rates to the patients and also by update them about adverse effects and the significance in overall patient treatment (e.g., by helping them to decide whether the advantages of treatment exceed the danger of adverse effects) (Bottorff 2006).

Active communication among health team members will enhance health care delivery outcome, increment physician fulfilment and decreases the expenses of medicinal services. A study showed that pharmacist, nurses and physicians were involved in most of the cases since they are the closest party to patients in managing the chronic disease. In another meta-analysis, the influence of pharmacist in helping the administration of hypertension found that an essentially more prominent probability of controlled blood pressure. The study features the reliable advantage of team-based care to enhance blood pressure control. Not much physical examination is needed to decrease the risk of hypertension (Olsson et al. 2002).

Telemedicine allows direct communication between patients and their healthcare team and it can be as simple as telephone-based care and digital technologies which provides new ways to virtually share information regarding health. Changing to patientcentred model that will comprise of team-based care from the disease-specific model is believed to be a key aspect of health care reform. Each team consisting of physician, nurse, or pharmacist including social workers, nutritionists, hypertension specialist, and community health workers for specific patients will work together from diagnosis step until the followup assessments. In conclusion, the formation of team-based care is effective in treating hypertension (Carter, Bosworth and Green 2012). Pharmacists can improve the patients' compliance regarding the low-density lipoprotein cholesterol (LDL) treatment by giving them 30-minute consultation about the importance of lipid level management and the role played by drug therapy in improving their cardiovascular risk. They are encouraged to do a followup treatment once a month to evaluate any reduction in LDL level of the patients (Bottorff 2006).

Regarding management of diabetes, community pharmacist has significant experience in the pharmacotherapy of diabetes and can make relevant medication treatment recommendations to doctors. Pharmacists are also qualified at recognising adherence problems and stating adverse drug consequences, many pharmacists are trained to counsel patients on diet, exercise, and diabetes self-cam activities (Doucette et al. 2009; George et al. 2010). The pharmacists play an important role in diabetes care by screening patients at high risk for diabetes, assessing patient health status and adherence to standards of care, educating patients to empower them to care for themselves, referring patients to other health care professionals, and monitoring outcomes of the medication used. Good communication skills a commitment of time, effort, and resources are required to provide

Malay J Pharm Sci, Vol. 16, No. 1 (2018): 45-54 
diabetes management services. Pharmacists who obtain training in diabetes management reap the rewards in professional satisfaction (Campbell 2002).

Also, as a disease that required mastery of psychomotor skill, one of the roles of community pharmacists is that they can efficiently show the correct technique of using an inhaler to the asthma patients (Basheti et al. 2005; George et al. 2010). Therefore it's possible to control asthma's symptoms, enhance the perception of asthma control and decrease absence from work or school (Saini, Krass and Armour 2004; George et al. 2010).

\section{Role of Pharmacist in Contraceptive Injection}

A study conducted by Heller to examine the acceptability of users receiving the subcutaneous form of the contraceptive injection from pharmacists in the community pharmacy setting. The respondents mentioned the advantages of community pharmacy such as quicker appointments, easier and nearer to go. Based on interviews with pharmacists, the participants said that they saw themselves as a "first port of call" and indicated that their contribution to health care enabled "freeing up" of doctors. Most pharmacists did not perceive the movement of maintaining the service during holiday leave to be a problem. Plus, pharmacists are pleased to develop the ability to administer the contraceptive injection. The pharmacist also felt that pharmacy was an appropriate place for women to receive contraceptive services and advice (Heller, Johnstone and Cameron 2017).

\section{Role of Pharmacists in Tropical Diseases}

Global warming and climate change which are the result of the greenhouse effect have caused the increase in the cases of tropical diseases. Some examples of these tropical diseases are: dengue fever, helminths, leishmaniosis, leprosy, filariasis, malaria, tuberculosis, onchocerciasis, African trypanosomiasis and schistosomiasis. Pharmacists play an important role in the eradication of the tropical diseases. During the prevention and treatment of the tropical diseases, the pharmacists play their roles as a communicator, quality drug supplier, collaborator, trainer and supervisor as a health promoter. Pharmacists should also participate in prevention and control programs. Immunisation delivery is one of the most common and basic preventive service that can be provided by the pharmacists. Nowadays, there are outbreaks in tropical diseases due to disaster. These phenomena require a large supply of medicines and vaccines as well as a large number of well-trained individuals, such as pharmacists. Therefore, pharmacists help in improving the health status of the population and enhance the public health system (Hammond et al. 2003; Pounds et al. 2006; Maity et al. 2013; Winslow 1920).

\section{Role of Pharmacists on Pneumococcal Vaccination in Elderly}

Elderly patients are the majority population that have the highest risk of fatal due to invasive pneumococcal disease. The absence of familiarity with vaccination is one of the most common reasons which can increase the chances of this risk. However, other than the physicians, there are other members in health care team that can take the role in improving disease prevention and vaccination for example pharmacist. Pharmacists definitely play a significant role regarding the vaccination among elderly. This was supported by the findings of the same study where almost all patients that communicate with pharmacists, reported already received the vaccination. For those who were not vaccinated, they were willing to get it under their physician recommendation. However, a high percentage of patients did 
not know that vaccination is available at some certified pharmacy. The study points out the importance of pharmacists on disease prevention. All of them carry a responsibility to guide the patients especially elderly people about the vaccination (Wong-Beringer, Brodetsky and Quist 2003).

\section{Role of Pharmacists in Safe and Appropriate Medication Use}

\section{Medical marijuana}

Pharmacists are well-known as medication experts and work to ensure safe and appropriate medication use. Role of pharmacists is shown in uses of medical marijuana as it poses a unique challenge and a novel opportunity for pharmacists.

In general, pharmacists should develop a systematic approach to dealing with the issue of medical marijuana. Pharmacists play an important role in keeping abreast of local, state and federal laws regarding medical marijuana. A qualified pharmacist should know all relevant procedures and protocols when practicing in areas with medical marijuana laws and also develop a working knowledge of the risks and benefits of medical marijuana. Not only that, pharmacists needs to conduct thorough medical and social histories to inquire about illicit drug use, including medical marijuana. Nowadays, people use marijuana as one of the options for their medication, so pharmacists need to consider all patients are treated for serious and chronic debilitating conditions as possible users of medical marijuana. Apart from that, it is responsible for pharmacists to screen patients who use medical marijuana or are inclined to use it for drug-drug and drug-disease interactions and counseling is needed to be given accordingly to every patient. If a patient appears to have a drug-induced disease, pharmacists should evaluate the role of marijuana as a causative agent (Seamon et al. 2007).

The possibilities when using marijuana as a medicine are patients had a tendency to addiction towards marijuana and more susceptible to psychological diseases, so pharmacists need to counsel about the risks associated with marijuana use. Also, pharmacists can ensure that the patients are using marijuana for medical purposes, after conducting medical and social histories checking under appropriate and continuous medical supervision from a physician. A patient who are receiving drug therapy for a serious, chronic or debilitating medical condition or resides in a state where medical marijuana is permissible to take marijuana as medication. Other than that, pharmacists should develop the necessary literature retrieval and evaluation skills to address drug information questions involving medical marijuana. Pharmacists should not give any recommendation about a source or provide specific instructions on how to obtain marijuana as marijuana are strictly under Control Substances Act (CSA) (Seamon et al. 2007).

\section{REDUCTION OF HEALTHCARE COSTS BY PHARMACIST'S INTERVENTIONS}

A literature review by Dalton and Byrne (2017) describes the increasing healthcare expenditure in global due to an aging population, technologies advance, and prevalence of medication errors. The role of pharmacists has transformed dispersing and supplying medicine to provide services in health promotion and disease prevention. Pharmacists play major roles in reducing cost by reviewing pharmacotherapy and reduction of prescribed medicine which will lead to Adverse Drug Reaction (ADR). The discontinuation of possible inappropriate medication in elderly should be done to reduce the risk of ADR (White, Arakelian

Malay J Pharm Sci, Vol. 16, No. 1 (2018): 45-54 
and Rho 1999). ADR often contribute to expensive and prolonged hospital admission, the rise in healthcare utilisation which further increases the medical costs. Pharmacists need to emphasise pharmacoeconomic evaluation studies by identifying and comparing the cost of different pharmacotherapies services. Appropriate changes in patients' treatment can save the cost of medicine. In managing chronic illness, community pharmacists can make a recommendation to patients or prescriber about pharmacotherapy that is ideal for the patient's condition and cost of medicine as they are extensively trained and equipped with the necessary knowledge (White, Arakelian and Rho 1999). Medication non-adherence can increase medication-related hospital admission which is an economic burden. Community pharmacists play an important role in patient adherence where they identify patients who do not take medicine as prescribed thus giving them appropriate counselling and education. Pharmacists can recommend patients to use generic medicines rather than high cost branded alternatives which help in lowering the cost. Community pharmacists can provide first aid for minor injuries to avoid high-cost trips to general hospitals, which is a waste of resources and time for both patients and general practitioners under minor ailment scheme. Delivery of additional services by community pharmacists can reduce patients to find for the expensive health-care sector (Dalton and Byrne 2017).

\section{CONCLUSION}

The role of pharmacists is changing continuously to meet the local needs throughout the world. This can be seen through the shifting from product-centred services to patientcentred services. Pharmacists have the potential to play an important role in both public and global health by providing information and advice on the therapeutic use of medicines. Clinical pharmacists play a big part in the multidisciplinary and interdisciplinary global health. Community pharmacist plays a crucial role in the management of chronic diseases such as asthma, arthritis, palliative care and pain, cardiovascular disease, diabetes and hypertension.

To improve the disease prevention in elderly, pharmacists also play a significant role in pneumococcal vaccination. Besides, pharmacists are important in drug therapy management and ensuring the safe and appropriate medication use to reduce healthcare cost. Lastly, the pharmacist should remain the sustainability of global healthcare system by guiding self-treating in minor ailments.

The challenge for pharmacists nowadays in global health is the limited public awareness about pharmacy services. Engagement of both local and international health bodies is recommended to achieve goals in a large population. Pharmacists should have finely attuned skills in providing quality healthcare services. Therefore, educators need to change their mind set to have a more balanced curriculum to foster the competency of pharmacy practitioners to empower the students. To further define the role of the pharmacists in global health, pharmacists must change their perception of what services they can provide and where these services can be applied. Intervention approaches that have proved effective in some settings are standard treatment guidelines, essential drugs list, pharmacy and therapeutics committees, problem-based basic professional training and targeted in-service training of health workers. 


\section{REFERENCES}

AMERICAN PUBLIC HEALTH ASSOCIATION (APHA). (2006) The role of the pharmacist in public health (Washington DC: American Public Health Association). www.apha.org/ advocacy/policy/policysearch/default.htm?id=1338 (11 November 2017).

BASHETI, I. A., REDDEL, H. K., ARMOUR, C. L. \& BOSNIC-ANTICEVICH, S. Z. (2005) Counseling about turbuhaler technique: Needs assessment and effective strategies for community pharmacists, Respiratory Care, 50: 617-623.

BELL, J., DZIEKAN, G., POLLACK, C. \& MAHACHAI, V. (2016) Self-care in the twenty first century: A vital role for the pharmacist, Advances in Therapy, 33(10): 1691-1703. https:// doi.org/10.1007/s12325-016-0395-5.

BOTTORFF, M. (2006) Role of the pharmacist, Pharmacotherapy: The Journal of Human Pharmacology and Drug Therapy, 26(12P2): 227S-232S.

CAMPBELL, R. K. (2002) Role of the pharmacist in diabetes management, American Journal of Health-System Pharmacy, 59: S18-S21.

CARTER, B. L., BOSWORTH, H. B. \& GREEN, B. B. (2012) The hypertension team: The role of the pharmacist, nurse, and teamwork in hypertension therapy, The Journal of Clinical Hypertension, 14(1): 51-65. https://doi.org/10.1111/j.1751-7176.2011.00542.x.

DALTON, K. \& BYRNE, S. (2017) Role of the pharmacist in reducing healthcare costs: Current insights, Integrated Pharmacy Research and Practice, 6: 37. https://doi.org/10.2147/ IPRP.S108047.

DOUCETTE, W. R., WITRY, M. J., FARRIS, K. B. \& MCDONOUGH, R. P. (2009) Community pharmacist-provided extended diabetes care, Annals of Pharmacotherapy, 43(5): 882-889. https://doi.org/10.1345/aph.1L605.

GEORGE, P. P., MOLINA, J., CHEAH, J., CHAN, S. C. \& LIM, B. P. (2010) The evolving role of the community pharmacist in chronic disease management: A literature review, Annals of the Academy of Medicine, Singapore, 39: 861-867.

HAMMOND, R. W., SCHWARTZ, A. H., CAMPBELL, M. J., REMINGTON, T. L., CHUCK, S., BLAIR, M. M. et al. (2003) Collaborative drug therapy management by pharmacists: 2003, Pharmacotherapy: The Journal of Human Pharmacology and Drug Therapy, 23(9): 1210-1225. https://doi.org/10.1592/phco.23.10.1210.32752.

HELLER, R., JOHNSTONE, A. \& CAMERON, S. (2017) The feasibility of contraceptive injections at the community pharmacy, The European Journal of Contraception and Reproductive Health Care, 22(5): 327-333. https://doi.org/10.1080/13625187.2017.13578 08.

INTERNATIONAL PHARMACEUTICAL FEDERATION (FIP). (2016) Pharmaceutical practice and the FIP sections (The Hague: FIP). https://www.fip.org/pharmacy_practice (11 November 2017).

Malay J Pharm Sci, Vol. 16, No. 1 (2018): 45-54 
MACFARLANE, S. B., JACOBS, M. \& KAAYA, E. E. (2008) In the name of global health: Trends in academic institutions, Journal of Public Health Policy, 29(4): 383-401. https://doi. org/10.1057/jphp.2008.25.

MAITY, T., PAHARI, N., BERA, K. \& GANGULI, S. (2013) A literature review on current tropical diseases and the role of pharmacist in public health with special reference to tropical diseases, BioMedRx, 1(1): 4-10.

NHS ENGLAND. (2015) Accelerate, coordinate, evaluate: Pharmacy training for early diagnosis of cancer, Pharmacy/primary care cluster interim report no. 2 (London: NHS England and Cancer Research UK). http://www.cruk.org/sites/default/files/ace_pharmacy_ training_report_final.pdf (12 November 2017).

OJI, V., WEAVER, S. B., FALADE, D. \& FAGBEMI, B. (2013) Emerging roles of US pharmacists in global health and Africa, Journal of Biosafety and Health Education, 1: 108.

OLSSON, E., TUYET, L., NGUYEN, H. \& LUNDBORG, C. S. (2002) Health professionals' and consumers' views on the role of the pharmacy personnel and the pharmacy service in Hanoi, Vietnam: A qualitative study, Journal of Clinical Pharmacy and Therapeutics, 27(4): 273-280. https://doi.org/10.1046/j.1365-2710.2002.00421.x.

POUNDS, J. A., BUSTAMANTE, M. R., COLOMA, L. A., CONSUEGRA, J. A., FOGDEN, M. P., FOSTER, P. N. et al. (2006) Widespread amphibian extinctions from epidemic disease driven by global warming, Nature, 439: 161-167. https://doi.org/10.1038/nature04246.

SAINI, B., KRASS, I. \& ARMOUR, C. (2004) Development, implementation, and evaluation of a community pharmacy-based asthma care model, Annals of Pharmacotherapy, 38(11): 1954-1960. https://doi.org/10.1345/aph.1E045.

SEAMON, M. J., FASS, J. A., MANISCALCO-FEICHTL, M. \& ABU-SHRAIE, N. A. (2007) Medical marijuana and the developing role of the pharmacist, American Journal of HealthSystem Pharmacy, 64(10): 1037-1044. https://doi.org/10.2146/ajhp060471.

STEEB, D. R., JOYNER, P. U. \& THAKKER, D. R. (2014) Exploring the role of the pharmacist in global health, Journal of the American Pharmacists Association, 54(5): 552-555. https:// doi.org/10.1331/JAPhA.2014.13251.

STRAND, M. A., TELLERS, J., PATTERSON, A., ROSS, A. \& PALOMBI, L. (2016) The achievement of public health services in pharmacy practice: A literature review, Research in Social and Administrative Pharmacy, 12(2): 247-256. https://doi.org/10.1016/j. sapharm.2015.06.004.

THE ROYAL PHARMACEUTICAL SOCIETY ENGLAND. (2013) New models of pharmacy: What is emerging and what is possible. A review of the literature (London: The Royal Pharmaceutical Society England).

TRAYNOR, K. (2005) US pharmacists respond to global AIDS crisis (Maryland, US: American Society of Health-System Pharmacists). 
VIVIAN, J. \& FINK III, J. (2008) Obra '90 at sweet sixteen: A retrospective review, US Pharmacist, 33(3): 59-65. http://www.uspharmacist.com/content/t/regulatory/c/10126/.

WHITE, T. J., ARAKELIAN, A. \& RHO, J. P. (1999) Counting the costs of drug-related adverse events, Pharmacoeconomics, 15(5): 445-458. https://doi.org/10.2165/00019053199915050-00003.

WINSLOW, C. -E. (1920) The untilled fields of public health, Science, 51(1306): 23-33. https://doi.org/10.1126/science.51.1306.23.

WONG-BERINGER, A., BRODETSKY, E. \& QUIST, R. (2003) Pneumococcal vaccination in hospitalized elderly patients: Role of the pharmacist, Pharmacotherapy: The Journal of Human Pharmacology and Drug Therapy, 23(2): 199-208. https://doi.org/10.1592/ phco.23.2.199.32085. 